\title{
What Is Well-Being In The Modern Society: Objective View
}

\author{
Elena Alatartseva ${ }^{1, a}$, Galina Barysheva ${ }^{1}$ \\ ${ }^{1}$ Tomsk polytechnic university, 634050 Lenina str., 30, Tomsk, Russia
}

\begin{abstract}
The topic of the well-being of human and society has always interested the great thinkers of the humankind. However, conceptually, as a problem of the state and public, this topic fully emerged only in the aftermath of the Second World War in the past century, and it became especially topical in the mid-60s, when a special organization was founded on the basis of the United Nations Organization, the United Nations Development Programme (UNDP, 1965). Well-being became a popular topic for various sociopolitical, socio-economic, cultural, and historical theoretical research and applied programmes. However, there is no unanimously agreed definition of this category or an unanimously agreed approach to its research and evaluation of its value and importance to the human and the society. The present article continues a cycle of the author's articles devoted to the research of human well-being in nowadays conditions. It looks into the basic concepts, conceptual grounds, and contradictions shaping the key aspects of this broad topic, as well as the fundamental causes and possible methodological misconceptions influencing both their development and the attitude to them of a human, society, state. The article provides extensive statistical data which illustrate the enormous, egregious ill-being of a large part of human society in the modern world. Also, in the article we have undertaken an attempt to define well-being as a multiple-aspect concept and to present a detailed analysis of fundamental causes of the modern ill-being on a massive scale.
\end{abstract}

\section{Introduction}

The topic of the well-being of human and society has always interested the great thinkers of the humankind. However, conceptually, as a problem of the state and public, this topic fully emerged only in the aftermath of the Second World War in the past century, and it became especially topical in the mid-60s, when a special organization was founded on the basis of the United Nations Organization, the United Nations Development Programme (UNDP, 1965). That organization was created in order to provide cooperation for countries in the realization of their sustainable development plans. From that moment on, well-being was considered a strategic global and regional (national) goal. Well-being became a popular topic for various socio-political, socioeconomic, cultural, and historical theoretical research and applied programmes. However, there is no separate branch of science or area of social, political, and economic knowledge which would study the well-being of human and society. Perhaps, it is due to the subjective nature of this concept. There is no unanimously agreed definition of this category or unanimously agreed approach to its research and evaluation of its value and importance to the human and the society. In turn, there are many interpretations of this category, depending on the aspect being considered. The fullest systematisation of the different aspects of this concept was presented by Inna Vladimirovna Merzlyakova in her dissertation thesis for the degree of Candidate of Social Science "Theoretical and Methodological Grounds for Sociological Analysis of the Social Well-Being of the Population of the Region" (2007). The systemisation introduced by Merzlyakova (2007) allows us to mark out several aspects of the concept of "human well-being". In the aspects of philosophy and ethics, society and psychology, moral and integrity, well-being is "the embodiment of moral virtues, mental harmony, happiness, and bliss" (as it was noted by Plato, Aristotle, Kant, J. Locke, V. Solovyov, B. Spinoza, Rousseau, E. Fromm, and other thinkers) and a "positive emotional state" (F. Herzberg, K. Rogers, A. Maslow, E. Fromm, and others). In the aspect of society and politics, wellbeing is "the strategic goal of the state's policy" (as it was understood by Plato, Aristotle, T. Hobbes, J. Bentham, J. Locke, N. Machiavelli, T. Jefferson, B. Spinoza, and other thinkers) and "the ideal social order" (for example, E. Durkheim, R. Dahrendorf, K. Marks, H. Spencer). In the aspect of society and economics, wellbeing is characterised as "material wealth, welfare, and riches" (J. Keynes, J. Galbraith, T. Malthus, D. Ricardo, A. Smith, A. Toffler, and other philosophers, sociologists, and economists) and "the result of coordinated social behaviour and efficient interpersonal

\footnotetext{
${ }^{\mathrm{a}}$ Corresponding author: alatartsevaea@bestracg.ru
} 
interaction" (M. Weber, G. Mead, G. Homans, and others). In the aspect of individuality and personality, well-being is considered to be "the physical, psychological, and social health" (G.P. Aponasenko, N.M. Amosov, A.L. Busygina, S.A. Mezentsev, and others) and "a harmonious relationship between natural environment and human" (I.V. Bestuzhev-Lada, J. Galbraith, V.I. Danilov-Danilyan, D.H. Meadows, D.L. Meadows, and others).

The mentioned characteristics of the "human wellbeing" category clearly illustrate the fact that this concept is a category which is subjective, multivalent, multifunctional, many-sided (multi-aspect), contextual, situational, and polysemantic. The contradictoriness of the contents and the meanings is born through the contextual nature of interpretations which, in its turn, is determined by the aspect and context that we choose as our discourse. The scientific approach to research universally applied in various sciences, especially in the exact ones, is to categorise the basic concepts in a precise manner: define them, classify them, distinguish their specific features, as well as to define the subject, object, method, and purpose of the research. Such approach is marked with a distinct applied relevance if the purpose of the research is not to mislead, withdrawing from the point and getting involved into sophistry, but to look objectively at the current reality, discover the cause-effect relationships and consistent patterns, evaluate the development of events, the participants of the said events, and the most probable consequences which will form a new reality. Another most important aspect of this approach is that it allows the formation of a unified, uniform language of communication which gives every participant of the process a chance to understand and interpret all the events, actions, results, and conclusions in a similar way.

\section{Human well-being: what is it?}

The social paradox is characterised by the fact that most people tend to discourse upon various socio-political, socio-economic, cultural, and historical arrangements of life and interactions, whether it be the economy, politics, business, society, education, upbringing, traditions and other aspects of them, in rather generalised terms, categories, and concepts. Here it is appropriate to mention a well-known aphorism by Kozma Prutkov who in his time said that "Many things are incomprehensible to us not because our comprehension is weak, but because those things are not within the frames of our comprehension." [1] Critical thinking is not inherent to the modern society as a whole. In spite of the abundance of available information, the majority of people, as a rule, do not take the trouble to analyse, comprehend, or specify the categories and concepts which they use when speculating about this or that issue unless it refers to exact and natural sciences. An enormous stream of information reports broadcast in various ways teems with terms or words which, along with their common meanings, are quite often charged with a different sense load and message. Universal values, freedom, equality, fraternity, rights, democracy, economy, economic growth, debt load, well-being, wealth, investment, consumer activity, consumer and effective demand, opposition, culture, education, health, happiness, etc. The list of such vague or, on the contrary, multivalent concepts, is very extensive. The many-sidedness of the meaningful content of such concepts is conditioned by the conceptual subjectivity of people defining and filling them up with meaning; such categories cannot be measured or described by unified, uniform measures and criteria. Their meaningful content is determined exclusively by the perceptions and attitudes of individuals who discourse on these categories. And those not talking part in the discourse take the judgement of others for an axiom, an unambiguous definition. At the same time, the sense load and message implied by a person discoursing on and translating such concepts and categories (at the same time defining them) may be perceived radically differently by a recipient though they all think that they talk about one and the same topic, making reference to complex concepts in belief that they are comprehended and interpreted in the same manner. Let us take a look at a simple example of such an unambiguous concept as "freedom" which is defined as one of the inalienable rights and values given to man by nature, and, in essence, forming the basis for human well-being. If we considered it from the subjective viewpoint, what would be the meaning of "freedom" to the following members of society: a politician, a prisoner, a slave (in the historical retrospect), a hostage, a woman happily or unhappily married, a person in the context of European or Arab cultures, an adolescent, a monk in a Tibetan monastery, a Buddhist, a patient of an ordinary clinics and that of a psychiatric one, a specialist working on a challenging project with a scheduled "dead-line" the success of which determines his or her future career and material remuneration, a disabled or elderly person, a terminally ill patient, an orphan confined in a children's home, and so on? And what does this concept mean for different ethnic communities and cultures as a whole, for example, for Indians and the Japanese, Italians and Arabs, Georgians and Dutch, the Chinese and Africans or for representatives of different religious denominations? And if we talk about this concept in the situational context, such as, for example, in the situation of a release of hostages, military occupation, peaceful protests of the opposition, a military conflict, natural disasters, man-made disasters, the completion of a multi-year training and receiving a long-awaited degree, in situations of absolute peace, tranquillity, harmony, and prosperity (if these are possible, of course) and so on? And, if we consider it from the vectorial and goal-oriented viewpoint, is "freedom" a goal as the ultimate result, or is it an effect (a consequence) of a result, or is it an initial premise without which it is impossible to achieve some objectives and expected outcomes, or it is an indispensable means to accomplish the intended purpose, or is it a process perceived as a continuous condition, a sensation, or a feeling? Ask yourself this question: what is it? And, if we consider it from the viewpoint of culture 
and history, what was "freedom" for people forty thousand, ten thousand, one thousand, one hundred years ago, yesterday, today; what will it be tomorrow and for future generations? Will it remain the same concept? If we consider this question in this light, it becomes apparent that "freedom", as a key characteristic of wellbeing, is a highly multivalent category marked with a varied perception of its meaning by different subjects of public relations in different situational and temporal conditions, and it will establish different socio-political, socio-economic, cultural, historical, and individualistic contexts. Therefore, each time this concept is used it must be clearly categorised and specified.

The logic of reasoning is grounded by the chosen vector of goals, and it should be applied in any situation when it comes to multivalued concepts if the pursued goal is the maximal objectification of the desired result and searched-for solution. A distortion of this logic suggests either a deliberate misrepresentation with a view to driving away from the truth, or some sociological ignorance leading to extremely negative consequences for human life and society [2].

Coming back to the concept of well-being, let us cite its definition from the The Brockhaus and Efron Encyclopedic Dictionary (1890-1907): "Благополучие то же, что счастье, всегда субъективно понимаемое под достижением всех благ, к которым стремится человек" ("Well-being is the same as happiness; it is subjectively understood as achieving all the good things of life that man strives to have."). Aristotle (1997) wrote that, in respect to "well-being", the only thing everybody agrees with is the name of this concept, but everybody understands its content differently. The generalised understanding of the human well-being" provided to us by psychology can be formulated as "the existence of human in accordance with their nature" [3]. The United Nations Development Program defines "human wellbeing" as "the opportunity of people to realise their potential as human beings" [4].

Thus, at this stage in the study, it is possible to emphasise four key conceptual components (characteristics) of the "human well-being" category: 1) a human has well-being if they exist in accord with their nature, their essence; 2) a human has well-being if they understand (are conscious of) what are good things of life for them and have an opportunity and intention to achieve these good things; 3) a human has well-being if they have an opportunity to realise their potential as human beings; 4) a human has well-being if the society constituting the grounds of the state creates conditions and provides opportunities for them to exist in accord with their nature, realise their potential as human beings, and achieve the good things of life that human strives to achieve. However, this conceptual definition immediately gives rise to questions requiring clarification so as to avoid any manipulation with this category in pursuit of these or those own interests. The main objective is to understand whether human wellbeing is the basis, the foundation, the basic premise, or an indispensable condition for normal society for its successful development and prosperity; or is human well-being the goal, end result, an indicator of a successful society and prosperous state at the present stage of civilization development?

The objective view on human well-being in the nowadays world is the following.

In our article published in the materials of the International Scientific Symposium "Society and Continuous Human Well-Being" (Tomsk, Russia, March 2014), we have already mentioned that the well-being of human and society has become an issue of the global scale; in other words, "an issue of the world scale and a task of prime importance and national significance for each individual state". (Alatartseva, Sakharova, Polshkova, 2014).

The strategic plan for the development of the world in 2014-2017 published in [5] emphasises sustainable human development, which, by the UNDP definition, is "the process of enlarging people's choices by expanding their capabilities and opportunities in ways that are sustainable from the economic, social and environmental standpoints, benefiting the present without compromising the future".

Let us look at the world we live in today. In the year 2008, the whole world was shaken by a financial, economic, and social crisis - the worst since the Second World War. It affected even the major economic powers. Besides, there have been several local crises in Greece, Portugal, Iceland, Spain, Ukraine, Latvia, and other countries, resulting in a mass-scale downfall of companies and financial ruin of ordinary people who lost jobs, their places of residence, and elementary means of existence. A few local wars broke out, the number of refugees multiplied, people faced epidemics of previously unknown illnesses, and other events happened that influenced human well-being negatively.

Only over the period from the second half of the 20th century up to the present moment, the world has experienced over 650 military invasions and armed conflicts, about 150 of them being military conflicts considered to be wars. Many of them are of a protracted nature and they continue nowadays; such as, for example, the war in Afghanistan, the 1948 Arab-Israeli War, the war in Iraq, and the tribal and interstate wars in Africa. As the result of the US military invasion, Yugoslavia was completely disintegrated which led to a few decades' worth step back in the development of the population of Kosovo, Serbia, Bosnia, and Herzegovina. At least 30 protracted military conflicts have been initiated already in the 21 st century. Moreover, at present the military conflicts in Egypt, Syria, Libya, and Palestine are escalating; "peaceful" protests that are close in their nature to armed and revolutionary conflicts have taken hold over a half of the world: Thailand, India, Greece, Spain, Venezuela, Columbia, Ukraine, Georgia, and many other countries.

In total, over the period from 1946 to 2000, approximately 110 million people died, among which about 30 million died as a result of military conflicts, 36 million people died by hunger, and about 20 million people died from illnesses and epidemics; the others died as a result of natural disasters, various man-made disasters, acts of terrorism, and suicides. If we compare 
the losses of the world population in the second half of the 20th century to the total losses for the period from 1901 to 2000, which constituted over 270 million people, including those who died as a result of military actions, i.e. over 59 million people, as a result of terroristic acts over 81 million people, as a result of hunger and epidemics - over 124 million people, we come to face a horrifying fact that the post-war time (as it is usually referred to), the age of prosperity, globalisation, computerisation, and information brought along human losses that constitute almost a half of the total losses for the 20th century [6]. Over the first 13 years of the 21 st century, according to different estimates, approximately 1.5 million people got killed in military conflicts [7].

Apart from military conflicts, the same years of the 21 st century have witnessed about 20 large scale terroristic acts; all of them happening in countries where there were no open armed conflicts, i.e. in "safe" countries during peaceful time. As a result of these terroristic acts, approximately 6 thousand people were killed, and about the same number of people was injured. This period has also witnessed 13 massive man-made disasters which have brought irreparable damage to the population, economy, and environment.

Stating the "visible encouraging progress" in the decreasing of the number of starving people (as it is usually delicately put - "undernourished people"), the UN declares directly that the absolute number of starving people has grown from 850 million people in $1980(20 \%$ of the world population) to 1 billion people in 2010 (15\% of the world population) [8]. Out of these, $63 \%$ live in Asia and the Pacific Ocean region, which make up $15 \%$ of the population, and $26 \%$ live in Africa which constitutes $25 \%$ of the population. However, simple arithmetic shows that the number of starving people in 1980 was $20 \%$ of the world population, and now the same $20 \%$ continue to starve. This is simply due to the fact that the growth of population is faster that the growth of the number of starving people although the $5 \%$ difference may simply be a statistic error $[9,10,11]$. According to NASA, WHO, and UNICEF (from different sources), every day approximately 40 thousand people die by starvation and undernourishment, and about 18 thousand of them are children. The Human Development Report of 2010 shows that the UN admits that, since 1990, the progress in healthcare has slowed down on the account of "dramatic regress in 19 countries where approximately $6 \%$ of the world population live and where life expectancy rates decreased to a level lower than that of 1970", and "the decrease in maternal mortality is far from the goal which was set for 2015", and the progress is extremely slow [8]. The causes for such slow progress and, to a significant extent, regress are poverty, armed conflicts, and such diseases of the 20th and 21st centuries as the epidemics of HIV and AIDS, various modifications of flu and other viruscaused diseases, and also civilisation-induced diseases, such as obesity, chronic fatigue syndrome (in other words, prolonged depression), neurasthenia, cardiovascular diseases, and so forth [12]. According to the WHO, over 100 million people died in the 20th century due to various causes connected with smoking, and, with this tendency kept up, this number will reach 1 billion people in the 21 st century. At the end of 2008, the rate of smoking-caused mortality was approximately 5.4 million people per year [13]. According to the WHO, in 2011 the number of drug addicts in the world was 210 million people, which is $3 \%$ of the population, leaving out of account those addicted to painkillers; moreover, the age of the first drug intake has lowered from 15-17 to 12-17. According to the WHO, the world population includes 140 million people suffering from alcoholism, and 2.5 million people die every year from causes connected with alcoholism. In the meantime, the WHO states that constant consuming of 8 or more litres of alcohol per capita per year leads to an irrevocable degradation of a nation [14]. According to "The Economist", in 2012 the world population consumed 7.44 billion litres of strong alcoholic beverages, such as vodka, whiskey, rum, and tequila, which did not include wine, brandy-type drinks, and beer which play a similarly destructive role [15].

"While 19 per cent of the rural population used unimproved sources of water in $2010, \ldots$ nearly half of the population in developing regions - 2.5 billion (authors' note: It is the population of Asia and the Pacific Ocean region and Africa) - still lacks access to improved sanitation facilities" [16]. And it is more than a third of the population of the world! And, if we add to these numbers the population of the developed countries that, for the most part, also do not have this access, the total number will be indeed terrifying. The residents of slum quarters now constitute almost 1 billion people. It is approximately $30 \%$ of the total urban population over the world. In Africa, over $60 \%$ of the population reside in slum quarters. Today, the tendency to impoverishment is evident: it is expected that, by 2020, approximately 1.4 billion people will reside in spontaneous settlements and slums [17].

There still exists gender inequality and violence against women. And almost $60 \%$ of all employed people are included in the phenomenon of "vulnerable employment" [16]. However, if we speak directly, "vulnerable employment" is, in fact, permanent unemployment which keeps the "vulnerably employed" in fear because at any given moment they may lose their jobs, or this job is only temporary from the very beginning. It undoubtedly influences labour efficiency and the psychological and emotional state of people and, overall, the quality of their lives. The level of unemployment in the world differs from $0 \%$ in Monaco and $95 \%$ in Zimbabve, and, according to estimates of the International Labour Organisation, the level of unemployment is not less than $6 \%$ on average and $13 \%$ among young people. The ILO does not see any tendency towards a decrease in these numbers; on the contrary, they expect a tendency towards the complication of search for stable work, especially among young and aged people. A stable growth of unemployment is noted in the countries of Eastern and Southern Asia and Africa. At present, this growth is manifesting in the developed countries as well, where 1 million people became unemployed in 2013 alone. Even in such a "successful" country as the USA, the level of unemployment after the crisis of 2008 is over $10 \%$, and 
among young people - approximately 20\% [18]. The research performed by the International Labour Organization (ILO) and the Organization for Economic Cooperation and Development (OECD) shows that the number of officially registered unemployed people in Spain is $26.8 \%$, in South Africa $-25.2 \%$, in Italy $-12 \%$, in the European Union and France - 11\% each, in Turkey $-8.3 \%$. The lowest numbers are in Korea $-3 \%$, China - 4.1\%, Japan - 4.1\%, India - 4.6\%, Mexico $5.2 \%$, Australia $-5.5 \%$, and in Russia - 12.1\%. The figures of both the official unemployment and "vulnerable employment", even leaving the data from beyond the realm of official statistics out of account, present a truly scary picture. The UN, in their "Millennium Development Goals Report 2013", proudly states that the task set in the year 1990 to halve the number of people living in extreme poverty, the indicator of which is a per capita income of 1-1.25 US dollars a day, has been successfully accomplished. The same report says that 1.2 billion people still live in extreme poverty. This is guile since there is no data on how much the daily per capita income of this half has increased, and what daily per capita income should be sufficient. Besides, there is always a question of the stability of this income. The report provides an additional gradation of poverty, such as people living on 1-1.25 US dollars a day are poor, people living on 1.25-2 US dollars a day are moderately poor, and people living on 2-4 US dollars a day are low-income. An obvious speculation of concepts was used in order to divert attention. In total, all these categories constitute $60.9 \%$ of the working population of the world, which is more than 1.5 billion people. It proves the fact of hidden labour exploitation.

The number of refugees and immigrants who changed their countries of residence due to various reasons including extreme poverty and unemployment had been 75 million people by the end of 2012 , and $65 \%$ of them were children. "Overall, the number of people uprooted by conflict or persecution in 2012 was at its highest level since 1994" [16]. The social orphanhood and common homelessness are progressing. According to the UNICEF, social orphans constitute $1.5 \%$ of the total number of children younger than 18 , and homeless children constitute almost $8 \%$ of the total number of children.

The UNDP Report 2010 gives us the following data: "The distance between the richest and the poorest countries has widened to a gulf. The richest country today (Liechtenstein) is three times richer than the richest country in 1970 . The poorest country today (Zimbabwe) is by approximately $25 \%$ poorer that the poorest country in 1970 (also Zimbabwe)" [8].

The number of officially registered suicides in the world is 1.1 million people per year on average, although medical experts suppose that the real number is about 4 million. Moreover, 19 million people every year commit suicide attempts that fail [19]. Having already a horrendously large scale of ill-being among evidently unhappy categories of the population and witnessing the growth of the number of suicides committed due to 800 various reasons by the WHO estimates $(41 \%$ of them are unknown, $19 \%$ are fear of punishment, $18 \%$ - mental illnesses, $18 \%$ - troubles at home, $6 \%$ - passions, $3 \%$ loss of money, $1.4 \%$ - satiety of life, and $1.2 \%$ - physical illnesses [19]), we can already speak of the ill-being of societies themselves. Also, from our point of view, this very fact is confirmed by the statistics of addressing to consulting psychologists in the most developed and, as it is normally thought, safe and happy countries, such as European countries and the USA, where approximately $40 \%$ of the population use services of psychologists. In Russia, this number is $10-15 \%$ [20].

In the face of such horrifying statistics, the UNDP insistently declares evident progress of social development in their published strategy "Millennium Development Goals" (2013). In its turn, in May 2011, the Organisation for Economic Cooperation and Development (OECD) issued an initiative on researching the quality of life as a measurement of human well-being (Better Life Initiative). The main component of this initiative is to measure well-being and social progress through the calculation of an integral value of "Your Better Life Index", based on a broad range of indicators including the national GDP. This index takes into consideration 11 key indicators which, according to their developers, characterise the quality of life and human well-being. These indicators are divided into two groups: the first group of the indicators characterises the quality of life and evaluates health, work-life balance, education and literacy, social relations, participation in public life and public control (civil activity), the quality of environment and ecology, personal safety, and subjective sense of well-being. The second group of indicators characterises directly the material well-being of human through the evaluation of such indicators as income and wealth, job and salary, and the conditions of residence. Within the frames of this initiative, the OECD prepared and issued the report "How's life? 2013 - Measuring Well-Being" (2013) which contains the most recent statistic data on various indicators characterising the quality of life.

There is no need to analyze the data presented in the report. They were already given the following generalised estimate: "The report "How is Life?" determined that welfare has grown over the last fifteen years: people became richer and received more chances to be employed. The living conditions improved, and the air pollution levels went down. However, there are significant differences inside each country and between countries. For some groups of population, in particular the less educated and low-income people, it is characteristic to fall behind on all parameters of wellbeing introduced in the Report" [21]. We will not pick on the fact that this estimate puts an equality mark between welfare and well-being despite the obvious difference between these categories in terms of meaning and essence. This estimate on its own is the evidence of a logical mistake, deliberate or well-meant, not only in the approaches to the estimate but also to the comprehension of human well-being and social progress when horrendous mass-scale ill-being of people and whole countries is ignored, and declarations are made, at the highest level, that the well-being of the world population is constantly growing. 
The international "Commission on the Measurement of Economic Performance and Social Progress" (the Stiglitz-Sen-Fitoussi Commission), created in 2008, in their 2009 Report on the Measurement of Economic Performance and Social Progress emphasises that it is critical and vital to have a system of measurement and correspondent indicators adequate to modern demands and tasks of economic and social progress, where the said measurement and indicators would be the ones constituting the essence of human life and influencing its quality: "...those attempting to guide the economy and our societies are like pilots trying to steering a course without a reliable compass" [22].

\section{Conclusion}

How can the world situation with human well-being be like that we described above? Most probably, it shows the evident substitution of causes for consequences, objectives for goals, and results for means. The management theory tells us that "the realisation of control in respect of undetermined goals under an undetermined hierarchy of their significance and under incompatibility of simultaneously set goals is objectively impossible" [2]. The axiom of strategic control is: if we evaluate correctly the vector of the current state (causes and symptoms), the vector of the goals (results and effects), and the vector of the control error (risks), then, most likely, the goal will be reached, the tasks will be solved, and the results will bring along the expected effects. Unless, of course, unforeseeable force-major factors appear, and, as it is known, such factors only include nature: all the other factors are man-made and depend on the influence of particular individuals or groups.

In our opinion, first of all, it is extremely important to admit, at the highest international level, the fact of egregious, rapidly increasing ill-being and to accentuate the research of the two key aspects which were specified by us in the article published in the materials of the International scientific symposium "Society and Continuous Human Well-Being" (Tomsk, Russia, 2014): "1. How is ill-being externalised? What categories or concepts are used to describe it? What determinants are used to measure the state of ill-being? What criteria can we use to clearly (nominally) distinguish the two categories of people: the ones having nominal well-being and the ones having nominal ill-being? 2. What are the fundamental causes of ill-being? Can they be eliminated? Which ones of these fundamental causes are affected by people themselves, and, therefore, depend solely on the person, and which ones are out of the person's control?" (Alatartseva, Sakharova, Polshkova, 2014).

\section{Acknowledgements}

The author would like to thank Igor Ardashkin, Irina Kashchuk and Fabio Casati for their discussion during the study and the anonymous referees for their constructive and useful comments on the paper.

\section{References}

1. Kozma Prutkov [electronic resource], Sidorov S.V. Web-site of a teacher/researcher. - URL: http://sisv.com/board/15-1-0-38 (2016)

2. Dostatochno obshchaja teorija upravlenija. Postanovochnye materialy uchebnogo kursa fakulteta prikladnoy matematiki I protsessov upravlenija (SPGU,Moscva: Konzeptual, 2012)

3. E. Fromm, Krisis psikhoanalisa. Dzen-buddizm (Moskva: Ayris-Press, 2004).

4. Beyond scarcity: Power, poverty and the global water crisis (UNDP Human Development Report, New York: Macmillan, 2006)

5. UNDP Strategic Plan: 2014-17 (UNDP,2013)

6. V.V. Erlikhman, The Losses of the World Population in the 20th Century, URL: http://lib.rus.ec/b/160911/read (2016).

7. Current wars and conflicts of the XXI century, http://www.warconflict.ru (2016)

8. The Real Wealth of Nations: Pathways to Human Development (UNDP Human Development Report. ,20th Anniversary Edition, New York: Macmillan, 2010)

9. Countries of the World - URL: http://ru.worldstat.info (2016)

10. Population, Worldstat, info- URL: http://ru.worldstat.info (2016)

11. Population and urbanization of Asia, Vip4ex URL: http://vip4ex.ru/24-naselenie-i-urbanizaciyav-azii.html (2016).

12. M. Yacyno, Kultura individualizma (Harkov: Humanitarnyj Centr Harkov, 2012)

13. Tobacco Could Kill One Billion By 2100, WHO Report Warns, Sciencedaily- URL: https://www.sciencedaily.com/releases/2008/02/080 210092031.htm (2008).

14. 25th anniversary of the fall of the Berlin Wall, Analytical Information Center "Gazeta"- URL: http://qazeta.net/2013/06/25 (2013).

15. Daily chart. High spirits, The Economist-URL: http://www.economist.com/blogs/graphicdetail/2013 /06/daily-chart-9 (2013)

16. The Millennium Development Goals (UN Report 2013, New York: UN, 2013)

17. Children in an urban World. The state of the World's children (UNICEF Executive summary, New York: United Nations Children's Fund, 2012)

18. The number of unemployed in the World in 2013 will grow by 5.1 million to 202 million - ILO, Agency of economic information "Prime" URL: http://1 prime.ru/Statistics/20130122/760662149.htm $1(2013)$

19. Statistics of suicide, Life project - URL: http://www.lossofsoul.com/DEATH/suicide/statistic .html (2014)

20. O. Kostyukhina, Corporate training and staff development - URL: http://psihologok.ru/news/news-10765.html (2012) 
21. How's Life? 2013: Measuring Well-being (OECD Better Life Initiative, France: OECD, 2013)

22. J. E. Stiglitz, A. Sen, J. Fitoussi, Report by the Commission on the Measurement of Economic Performance and Social Progress (2009) 